\title{
Specialty Grand Challenges in Separation Processes
}

\author{
Eric Favre* \\ Laboratoire Réactions et Génie des Procédés, Université de Lorraine, Nancy, France
}

Keywords: separation, processes, energy, sustainability, challenge

\section{INTRODUCTION}

Separation processes have continuously been used and improved by mankind for the production of food, various products, and energy (Hougen, 1977). Early target operations, such as salt recovery from brine or seawater by evaporation, ore treatment for metal extraction (e.g., iron, silver, lead, mercury, etc.), and the synthesis of chemical products like alum for the textile industry, have been reported for centuries ${ }^{1}$. Thermal processes, such as evaporation or distillation, have been favored for a long time, but extractions based on an auxiliary phase (i.e., the use of a dedicated gas, liquid, or solid compound in order to generate a separation effect) have also been explored and used later on. For instance, silver extractions from ore thanks to mercury or alcohol dehydration with desiccant solids have been described in documents dating back from as early as the fifteenth century (Aris, 1977).

Through the ages, a large portfolio of techniques has gradually been invented and developed for multiphase, solid, gaseous, and liquid mixtures. Depending on the classification type, a variety of 20 to 100 operations can be listed today, including mechanical, thermal, auxiliary phase, and membrane separation processes (King, 1980). With the emergence of chemical engineering concepts in the late nineteenth century, and the spectacular expansion of chemical plants after WWII driven by the oil and gas industry, separation processes are today classically considered as one of the pillars of chemical engineering (Peppas and Harland, 1989). The importance of separation processes is highlighted by the so-called Sherwood plot (Sherwood et al., 1975), which links the degree of dilution of a target molecule at the outlet of a production process to its price. The spectacular increase of cost with dilution is explained as being a result of the increasing complexity and cost of separation processes in the downstream purification part. Another indication of the importance of separation processes comes from the fact that they are classically considered to represent 60 to $80 \%$ of the CAPEX (equipment) and OPEX (energy requirement) of production costs in Chemical Process Industry (CPI) plants (Humphrey and Keller, 1997).

Thanks to intense research efforts and industrial practice and feedback, a large number of separation processes can today be rationally designed, scaled, and controlled (Seider et al., 2009). Process Systems Engineering toolboxes indeed offer the possibility of quickly simulating and investigating the performances of a separation system (most often including a set of unit operations). The combination of mass and energy balances, fluid phase equilibria, and rate processes offer a generic methodology, which can, in principle, be applied to any type of molecule in the feed mixture for a rational design (Noble and Agrawal, 2005).

Today, CPIs produce around $10^{5}$ different molecules at capacities ranging from less than one kilo to 300 million tons per year (Amundson, 1988). The number of potential feed compositions to be treated by separation processes for industrial applications is thus enormous. Generally speaking, the most effective separation process for a given target application can be identified based on a series of efficiency indicators: the first one logically addresses the possibility of reaching the specifications

\footnotetext{
${ }^{1}$ Agricola (1556) De Re Metallica.
} 
imposed by the application (e.g., purity and recovery). The energy requirement and the productivity of the process are also of major importance, as are the environmental and risk efficiencies (quantity of waste generated, explosion hazard, etc.). All in all, the overall specific cost is usually taken as the ultimate objective function for the process selection and design study. It is important to stress that it is often more relevant to include all the equipment of a production system (e.g., reactors, heat exchangers, compressors, pumps, etc.) in a global optimization study in order to achieve an efficient process selection and design. Based on the state of the art outlined above, it could be concluded that no further research and/or development of separation processes is needed given the maturity of the discipline. The exact opposite is discussed in the following. A revolution is considered to be underway, and there are numerous scientific and technological challenges to be faced.

\section{SEPARATION PROCESSES OF TOMORROW: A NEW LANDSCAPE}

Existing separation processes and production plants have been designed according to a framework that will be considerably changed for several reasons:

- In terms of feedstocks, the CPIs of today use fossil resources (oil, natural gas, and coal) almost exclusively (Agrawal, 2001). A shift to renewable raw materials (e.g., starch, cellulose, lipids, or proteins extracted from plants or trees), through the biorefinery concept, is under intense investigation and will profoundly modify the processes and design methodology. Feed mixtures from biorefineries are indeed aqueous (rather than organic for classical, oil-based refineries) and complex, and the target molecules are often diluted and sensitive to heat. The position of distillation, often considered as the workhorse of separation processes, will thus change completely (Huang et al., 2008). Besides biorefineries, more advanced concepts, such as e-refineries based on electricity as the energy vector and $\mathrm{CO}_{2}$ as the carbon source, are also currently being investigated. It is obvious that the place and role of separation processes here will strongly differ compared to oil refineries.

- As separation systems require a large amount of energy, energy availability is another key issue (Null, 1980). For decades, thermal energy (and associated separation processes such as distillation) has been preferentially chosen in CPIs (Koros, 2004). Energy efficiency is nowadays of crucial importance, and the trend is to ideally combine heat and electricity (produced, if possible, by renewable technologies) in order to improve the overall efficiency. The gain that could be obtained through energy-efficient separation processes and/or production systems is significant (Sholl and Lively, 2016). Moreover, it is likely that the new production units will make use of distributed, decarbonized, and digitalized energy systems. The old centralized, fossiland thermal-based energy framework is no longer used as the reference.

- Environmental issues must be considered when dealing with production processes and make up some one of the most stringent selection criteria today. The inventory of waste production, water use, and greenhouse gases (C and water footprint) has a strong impact on the decisions that are made regarding a production system design or retrofit (Anastas and Zimmerman, 2003). The 3Rs (Reduce, Recycle, and Reuse), as well as the necessity to perform Life Cycle Analyses on each new process design, generate a new set of constraints.

- Last but not least, a paradigm shift in the economy is currently ongoing. With the advent of circulareconomy, lean-manufacturing, distributed, zerotime, zero-default, and consumer-based production schemes, the rules and methodologies that have been governing process design heuristics is changing (Clift, 2006). Again, this should affect the type, place, and role of separation processes in future production systems.

The new landscape detailed above must be addressed thanks to a rigorous, efficient strategy. The associated challenges are discussed in the next paragraph.

\section{SCIENTIFIC AND TECHNOLOGICAL CHALLENGES}

\section{Multiscale Modeling}

The rigorous design of a separation process should ideally cover a full understanding of processes at the molecular, unit process, and overall system level. The resulting multiscale modeling challenge is far from achieved today, especially when complex fluids (polymers, ion systems, etc.) and/or complex separation systems (porous media, reacting fluids, etc.) are involved (1987). Significant advances have recently been made at the molecular scale, especially thanks to developments in molecular dynamics. Phase equilibria situations can be predicted with decent precision in a great number of cases; however, major unknowns and errors remain when transfer processes or reacting systems are tackled. With the development of efficient predictive tools, we could in future see the emergence of computer-aided separation process designs.

\section{Energy Efficiency and Process Intensification}

While the energy requirement is often evaluated when selecting separation technologies, the general problem of energy efficiency strategies for separation processes remains under investigation (Castel and Favre, 2018). In this new energy environment, there is a crucial need for dedicated methodologies that consider and strive toward the development of optimal energy efficiency strategies. The combination of heat and power networks, connected to a series of separation processes (and ancillary equipment), call for new approaches. The question of an optimal driving force for separation (such as heat or pressure for absorption, adsorption, or membrane processes, for instance) is of particular interest but remains largely unexplored. Alternatively, pushing the productivity and energy efficiency corresponds to a major target in the approach of process intensification (Van Gerven and Stankiewicz, 2009). 


\section{Advanced Computing and Process Synthesis}

High Performance Computing (HPC) offers tremendous possibilities for chemical engineering in general and separation processes in particular. Complex separation schemes, hybrid processes, combined reaction and separation systems can be designed through so-called process synthesis methods. The very large combinatorial problem of such systems has for a long time been a barrier to systematic design studies, but modern methods, such as neural networks, machine learning, or superstructure programs, are opening up new horizons.

\section{Innovation Through Novel Structures and Production Technologies}

The endless creativity of chemists and material scientists is continuously giving rise to new possibilities for separation processes (2005). New separating agents, such as ionic liquids for absorption, Metal Oxide Frameworks (MOF) for adsorption (Gascon and Kapteijn, 2010), graphene (Geim, 2009), or carbon-based membranes have recently been reported to enable impressive separation possibilities. Bioinspired approaches have led to novel separation processes, such as aquaporins (de Groot and Grubmüller, 2001) for water desalination or carbonic anhydrase for carbon capture; the properties of biomolecules can be a source of inspiration for novel separation processes. In terms of production techniques, 3D printing opens for impressive possibilities for generating complex shapes. This could be of major interest for new packings (distillation, absorption, and extraction) or chromatographic systems (e.g., monoliths). The generic question of optimal shape for maximal mass transfer and minimal energy dissipation through pressure drop (Lightfoot, 1987) can thus be reconsidered thanks to these new production tools.

\section{TOWARD SUSTAINABLE PROCESSES AND PRODUCTION SYSTEMS}

The new set of constraints and the challenges detailed in the two previous paragraphs can play a key role in creating new sustainable matter and energy production systems. It can be anticipated that the design of novel, efficient, and sustainable separation processes will be of major importance to numerous industrial targets.

Biotechnology and biorefineries are known to make use of a large number of separation techniques, most of which are non-thermal. The downstream processing chain corresponds to the dominant cost of biomolecule production (Belter et al., 1988). The future environment of CPIs will be close to that of the bioindustry.

The same situation holds for the pharmaceutical and health sectors, where heat-sensitive molecules often have to be extracted from complex fluids. Alternatively, breakthrough innovations could be achieved for compact, autonomous, energyefficient devices such as artificial lungs, blood dialysis modules, active compound-dispensing units, or personal oxygenators. Recognizing that separation processes are, generally speaking, mass exchanger systems, innovations or new designs in this domain could be beneficial to controlled release or medical devices.

Nevertheless, the most significant expectations surrounding advanced separation processes are probably those related to the water and energy sectors. The production of drinking water and the treatment of wastewater have historically made use of a portfolio of separation processes. The quest for energy-efficient and intensified production systems is still ongoing: the firstgeneration evaporation processes for the production of drinking water have gradually been replaced by reverse osmosis units, and this is mostly due to the superior energy efficiency of the membrane systems (Elimeleh and Phillip, 2011). It could be that innovative ion exchange resins, electrochemical processes, or solar-based evaporation processes offer interesting perspectives in the near future (Agrawal and Mallapragada, 2010). Energy recovery from seawater by pressure-retarded osmosis or reverse electrodialysis concepts are also intensively investigated in order to enhance the energy efficiency of water treatment systems. The large carbon footprint of the current energy production plants (coal power plants) and the advent of renewable heat and electricity production systems finally provide a formidable challenge for separation processes: carbon capture use and storage (CCUS) is mostly a separation process challenge (House et al., 2011) that could play a decisive role for greenhouse gases mitigation. Hydrogen production, be it from natural gas steam reforming, water electrolysis, or biomass gasification, requires efficient extraction and purification techniques. These challenges cover a very broad range of sizes and correspond to complex integrated systems for which the existing methodology and toolboxes have yet to be evaluated and improved (Chu and Majumdar, 2012).

\section{OVERVIEW}

Quoting Danckwerts (1966), "It will be a great mistake to think of the content of chemical engineering science as permanently fixed. It is likely to alter greatly over the years in response to the changing requirements of industry and to new scientific discoveries and ideas for their application." This statement certainly applies to separation processes. The combined effect of scientific push (new tools and new methods) and application pull (new feedstocks and new constraints) outlined above is likely to produce significant advancements with high impact on our society. A joint effort between academics and industrial players, in combination with multidisciplinary research, is needed to pave the way toward a sustainable matter and energy transformation system.

\section{AUTHOR CONTRIBUTIONS}

The author confirms being the sole contributor of this work and has approved it for publication. 


\section{REFERENCES}

(1987). Separation \& Purification: Critical Needs and Opportunities. Washington, DC: National Academy Press; Board on Chemical Sciences and Technology.

(2005). Materials for Separation Technologies: Energy Emission Reduction Opportunities. Oak Ridge, TN: Oak Ridge National Laboratory.

Agrawal, R. (2001). Separations: perspective of a process developer / designer. AIChE J. 47, 967-971. doi: 10.1002/aic.690470503

Agrawal, R., and Mallapragada, D. (2010). Chemical engineering in a solar energydriven sustainable future. AIChE J. 56, 2762-2768. doi: 10.1002/aic.12435

Amundson, N. R. (1988). Frontiers in Chemical Engineering. Research, Needs and Opportunities. Washington, DC: National Research Council. National Academic Press.

Anastas, P. T., and Zimmerman, J. B. (2003). Design through the twelve principles of green engineering. Environ. Sci. Technol. 37, 95-101. doi: 10.1021/es032373g

Aris, R. (1977). Academic chemical engineering in an historical perspective. IEC Fundam. 16, 1-4. doi: 10.1021/i160061a001

Belter, P. A., Cussler, E. L., and Hu, W. S. (1988). Bioseparations: Downstream Processing for Biotechnology. New York, NY: John Wiley \& Sons.

Castel, C., and Favre, E. (2018). Membrane separations and energy efficiency. J. Membr. Sci. 548, 345-357. doi: 10.1016/j.memsci.2017. 11.035

Chu, S., and Majumdar, A. (2012). Opportunities and challenges for a sustainable energy future. Nature 488, 294-303. doi: 10.1038/nature11475

Clift, R. (2006). Sustainable development and its implication for chemical engineering. Chem. Eng. Sci. 61, 4179-4187. doi: 10.1016/j.ces.2005. 10.017

Danckwerts, P. V. (1966). The Chemical Engineer. Sci. Chem. Eng. 13, 155-159.

de Groot, B. L., and Grubmüller, H. (2001). Water permeation across biological membranes: mechanism and dynamics of aquaporin-1 and glpf. Science 294, 2353-2357. doi: 10.1126/science.1062459

Elimeleh, M., and Phillip, W. A. (2011). The future of seawater desalination: energy, technology, and the environment. Science 333, 712-717. doi: $10.1126 /$ science. 1200488

Gascon, J., and Kapteijn, F. (2010). Metal-organic framework membranes - high potential, bright future? Angew. Chem. Int. Ed. 49, 1530-1532. doi: 10.1002/anie. 200906491

Geim, A. K. (2009). Graphene: status and prospects. Science 324, 1530-1534. doi: $10.1126 /$ science.1158877

Hougen, O. A. (1977). Seven decades of chemical engineering. Chem. Eng. Prog. 77, 89-104.
House, K. Z., Baclig, A. C., Ranjan, M., van Nierop, E., Wilcox, J., and Herzog, H. (2011). Economic and energetic analysis of capturing $\mathrm{CO} 2$ from ambient air. Proc. Natl. Acad. Sci. U.S.A. 108, 20428-20433. doi: 10.1073/pnas.1012253108

Huang, H. J., Ramaswamy, S., Tschirner, U. W., and Ramarao, B. V. (2008). A review of separation technologies in current and future biorefineries. Separ. Purif. Technol. 62, 1-21. doi: 10.1016/j.seppur.2007.12.011

Humphrey, J. L., and Keller, G. E. (1997). Separation Process Technology. New York, NY: MacGraw Hill.

King, C. J. (1980). Separation Processes, 2nd Edn. New York, NY: McGraw-Hill.

Koros, W. J. (2004). Evolving beyond the thermal age of separation processes: membranes can lead the way. AIChE J. 50:2326. doi: 10.1002/aic.10330

Lightfoot, E. (1987). What are dilute solutions? Separ. Sci. Technol. 22, 165-189. doi: $10.1080 / 01496398708068947$

Noble, R. D., and Agrawal, R. (2005). Separation research needs for the 21st century Ind. Eng. Chem. Res. 44:2887. doi: 10.1021/ie0501475

Null, H. R. (1980). Energy economy in separation processes. Chem. Eng. Prog. 42, 47-56.

Peppas, N. A., and Harland, R. S. (1989). One Hundred Years of Chemical Engineering. Boston, MA: Kluwer Academic Publishers, 125-142. doi: 10.1007/978-94-009-2307-2_7

Seider, W. D., Seader, J. D., and Lewin, D. R. (2009). Product \& Process Design Principles: Synthesis, Analysis and Evaluation. New York, NY: John Wiley \& Sons.

Sherwood, T. K., Pigford, R. L., and Wilke, C. R. (1975). Mass Transfer Operations. New York, NY: McGraw-Hill.

Sholl, D. S., and Lively, R. P. (2016). Seven chemical separations to change the world. Nature 532, 435-437. doi: 10.1038/532435a

Van Gerven, T., and Stankiewicz, A. (2009). Structure, energy, time - The fundamentals of process intensification, Indus. Eng. Chem. Res. 48, 2465-2474. doi: $10.1021 /$ ie $801501 y$

Conflict of Interest: The author declares that the research was conducted in the absence of any commercial or financial relationships that could be construed as a potential conflict of interest.

Copyright ( $\odot 2020$ Favre. This is an open-access article distributed under the terms of the Creative Commons Attribution License (CC BY). The use, distribution or reproduction in other forums is permitted, provided the original author(s) and the copyright owner(s) are credited and that the original publication in this journal is cited, in accordance with accepted academic practice. No use, distribution or reproduction is permitted which does not comply with these terms. 